\title{
Influence of Occlusal Disorders, Food Intake and Oral Hygiene Habits on Dental Caries in Adolescents: A Cross-Sectional Study
}

\section{Letizia Perillo ${ }^{1}$, Fabio Cocco $^{2}$, Maria Grazia Cagetti ${ }^{3}$, Davide Giugliano ${ }^{1 *}$, Elena Bardellini ${ }^{4}$, Francesca Amadori ${ }^{4}$, Guglielmo Campus ${ }^{5}$ and} Alessandra Majorana ${ }^{4}$

${ }^{1}$ Multidisciplinary Department of Medical-Surgical and Dental Specialties, Second University of Naples, Naples, Italy

${ }^{2}$ Department of Chemistry, University of Sassari, Sassari, Italy

${ }^{3}$ Department of Health Sciences, University of Milan, Milan, Italy

${ }^{4}$ Department of Pediatric Dentistry, Dental School, University of Brescia, Brescia, Italy

${ }^{5}$ Department of Surgery, Microsurgery and Medical Sciences, Dental School, University of Sassari, Sassari, Italy

\begin{abstract}
Objective: Dental caries is one of the most common oral diseases affecting children and adolescents. The complex multifactorial etiology of caries involves the host's characteristics (saliva and tooth enamel), the oral microflora (bacterial plaque), and the substrate (oral hygiene and diet). The aim of the present epidemiologic study was to calculate the DMFT (Decayed, Missed, Filled Teeth) index and to investigate the association between carious lesions with malocclusions, cariogenic food intake and oral care habits in 12-year-old schoolchildren in Southern Italy.
\end{abstract}

Materials and methods: The study sample involved school children attending the 2-year secondary school (corresponding to the eighth grade) of state-funded schools in Naples, in the South of Italy. Children were examined to detect dental caries and occlusal variables; moreover, a questionnaire to find out food and oral hygiene habits was obtained. The association among occlusion variables, oral health, dietary habits, and caries was statistically assessed with the one-way ANOVA, the odds ratio and the $x^{2}$ (Chi-Squared test) tests for evaluating the significance. The significance level was set at 0.05 .

Results: The study showed a lack of association between diet and oral hygiene and caries prevalence in 12-yearold boys and girls, on the contrary, there was a positive association between crossbite and caries.

Conclusion: Positive relationship was found between dental caries, parents' socioeconomic status and crossbite, whereas carious lesions, food intake, oral hygiene and the other type of occlusal disorder did not reveal any significant association.

Keywords: Carious lesions; Malocclusions; Cariogenic food intake; Oral care habits; Social status

\section{Introduction}

Dental caries is a very common oral disease affecting children and adolescents throughout the world, though data from developed countries suggest a decline of dental caries in the last 30 years [1-5] (Table 1).

The complex multifactorial etiology of caries involves the host's characteristics (saliva and tooth enamel), the oral microflora (bacterial plaque), and the substrate (oral hygiene and diet) [3]. Occlusal disorders, like dental crowding and crossbite, may be a risk factor for dental caries. Crowding unsettles normal interproximal tooth contacts with improper embrasures leading to food accumulation and plaque retention [6]. In Italy, relatively few researches have been performed on caries prevalence to date [7-10], sometimes focusing in restricted geographic areas. Even more, poor information is available in literature [11-14]. Thus, more information is needed specially to support some useful prevention programs.

The aim of the present epidemiologic study was to calculate the DMFT (Decayed, Missed, Filled Teeth) index and to investigate the association among carious lesions and malocclusions, cariogenic food intake and oral care habits in 12-year-old school children in Southern Italy.

\section{Materials and Methods}

\section{Sample selection}

The study sample involved school children attending the 2-year secondary school (corresponding to the eighth grade) of state-funded schools in Naples, in the South of Italy [15]. 48 schools were randomly selected from an initial pool of 79 schools, according to a cluster sample design previously identified by the school district to avoid selection bias ensuing from social heterogeneity. Classes within each school were sampled systematically. All students recruited in the sampled classes were examined, both to improve study feasibility and also to avoid any discriminations among pupils in the same school class. A total of 987 students were randomly selected, and a written consent to perform the examination was obtained from the children and their parents. The sample size was calculated assuming a $50 \%$ of prevalence ratio for each characteristic to be estimated, and a precision of the estimate of \pm 3 with a $95 \%$ confidence interval (sampling from finite population, nQuery Advisor, v. 4.0, Statistical Solution Ltd, Cork, Ireland). This assumption leads to the highest sample size with the given precision.

All the selected children were present at the schools on the day of the examination (867 subjects) participated in the study. Students who had already finished their orthodontic treatment and those who were undergoing a treatment at the time of the study were excluded.

*Corresponding author: Davide Giugliano, Multidisciplinary Department of MedicalSurgical and Dental Specialties, Second University of Naples, Via L. De Crecchio, 6 80138 Naples, Italy, Tel:+39 0815665501; E-mail: davide.giugliano@gmail.com

Received December 10, 2015; Accepted January 09, 2016; Published January 16, 2016

Citation: Perillo L, Cocco F, Cagetti MG, Giugliano D, Bardellini E, et al. (2016) Influence of Occlusal Disorders, Food Intake and Oral Hygiene Habits on Dental Caries in Adolescents: A Cross-Sectional Study. Dentistry 6: 358. doi:10.4172/2161 1122.1000358

Copyright: $\odot 2016$ Perillo L, et al. This is an open-access article distributed under the terms of the Creative Commons Attribution License, which permits unrestricted use, distribution, and reproduction in any medium, provided the original author and source are credited. 


\begin{tabular}{|c|c|c|c|c|c|c|}
\hline Authors & Year & Area & Sample Size & Age (Years) & DMFT & Prevalence \\
\hline Angelillo et al. & 1998 & Catanzaro & 385 & 12 & - & $88.1 \%$ \\
\hline Szoke et al. & 2000 & Ungheria & 900 & 12 & - & $84.5 \%$ \\
\hline Nieto et al. & 2001 & Spagna & 347 & $7-12-14$ & 3.91 & - \\
\hline Auad et al. & 2009 & Brasile & 458 & $13-14$ & 3.95 & $78 \%$ \\
\hline Mtaya et al. & 2009 & Tanzania & 369 & 12 & - & $22 \%$ \\
\hline Migale et al. & 2010 & Cutro & 103 & 11 & 2.60 & - \\
\hline Mazza et al. & 2010 & Burkina Faso & 354 & 12 & - & $22.9 \%$ \\
\hline
\end{tabular}

Table 1: Prevalence of dental caries and DMFT in 12 year old children.

\begin{tabular}{|c|c|c|c|}
\hline & $\begin{array}{c}\text { DMFT } \\
(\text { Mean } \pm \text { SE) }\end{array}$ & $\begin{array}{c}\text { DT } \\
(\text { Mean } \pm \text { SE) }\end{array}$ & $\begin{array}{c}\text { MT } \\
(\text { Mean } \pm \text { SE) }\end{array}$ \\
\hline Total & $1.88 \pm 0.09$ & $1.52 \pm 0.08$ & $0.07 \pm 0.02$ \\
\hline Boys & $1.71 \pm 012$ & $1.36 \pm 0.11$ & $0.07 \pm 0.03$ \\
\hline Girls & $2.02 \pm 0.13$ & $1.65 \pm 0.12$ & $0.07 \pm 0.02$ \\
\hline ANOVA & $F=2.94 ; p=0.09$ & F=3.32; $p=0.07$ & $0.28 \pm 0.05$ \\
\hline
\end{tabular}

Table 2: Caries index and subcomponents by total population and gender.

Therefore, the final sample to analyze comprised of 536 orthodontically untreated subjects.

The students were examined in a quiet classroom of their school without external interference, under natural or artificial illumination, approximately for 15 minutes. The dental occlusion assessment was carried out using latex gloves, sterile dental mouth mirrors and millimeter rulers. Personal data and information about orthodontic treatment were obtained directly from each student. No radiographs, study casts, or previous written records were used. The two examiners (Prof. Perillo and Dr. Giugliano) had previously undergone calibration to standardize their procedures before carried out clinical examination. The examination was focused on oral hygiene, occlusal variables and the evaluation of decayed (D), missing (M) and filled (F) teeth (T), or DMFT index [16]. Missing teeth were considered only if they were missing for caries $[17,18]$.

The orthodontic variables considered were molar relationship, overjet and overbite, posterior crossbite, scissor bite, crowding and diastema. In particular, the molar relationship was determined like the relationship between the upper and lower first permanent molars according to the Angle's classification; patients with subdivision malocclusions were included in the Class II or Class III groups on the basis of the predominant occlusal characteristic, or of the relationship between the canines. Overjet and overbite with values between 0 and 4 $\mathrm{mm}$ were considered normal. A posterior crossbite, unilateral (right or left) or bilateral, was diagnosed when a crossover of at least one tooth was detected in the posterior segments of the dental arches. A scissor bite was considered when the palatal cusps of the upper molars were positioned buccally in relation to the buccal cusps of the lower molars. Crowding and diastema were recorded for the anterior or the posterior segments. A midline diastema was considered to be present when there was a space of at least $2 \mathrm{~mm}$ between the maxillary central incisors.

\section{Questionnaire}

Information about oral hygiene and dietary habits was obtained with a questionnaire on daily oral hygiene practices, intake and frequency of different types of foods (i.e., carbohydrates, dairy products, sweets). The frequency of dental check-ups was also investigated.

Regarding parents' scholarly level, a distinction was made between low educational level (no education or compulsory schooling) and high/medium educational level (apprenticeship training, vocational school, high school or higher education) $[5,17,19]$.

\section{Statistical analysis}

DMFT values for each subject were used. The association between occlusion variables, oral health, dietary habits, and caries was assessed with the one-way ANOVA, the odds ratio and the $\chi^{2}$ tests for evaluating the statistical significance. The significance level was set at 0.05 .

\section{Results}

The study sample was composed of 536, 12-year old students (283 females, 253 males). Dental caries were recorded in 321 (59.8\%) students. No difference was observed in the prevalence of caries between gender $\left(\chi^{2}=0.70, p=0.40\right)$ or the different school districts $\left(\chi^{2}=5.52\right.$, $\mathrm{p}=0.70)$. The mean value of DMFT was $1.81 \pm 2.02(1.94 \pm 2.11$ in girls and $1.67 \pm 1.9$ in boys, one-way ANOVA $\mathrm{F}=0.77, \mathrm{p}=0.65)$; the decay (D) component was the most represented $(1.45 \pm 1.80)$ (Table 2$)$. The first permanent maxilla molar was the most affected by caries $(46.83 \%)$ and the least prevalence was for the lateral incisors (0.34\%) (Table 3).

Table 4 showed the distribution of the sample according to the occlusal variables. The first molar class was the most represented occlusion (59.41\%), followed by second (35.66\%) and third $(4.94 \%)$ class. Overjet and overbite were normal for most students. A midline deviation was detected in the $32.09 \%$ of the sample, while the presence of crossbite was recorded in the $11.75 \%$ of the sample. Crossbite was the only occlusal variable significantly associated to caries experience $\left(\chi^{2}=3.96, p=0.04\right)$ (Tables 5 and 6). Crowding was more present in subjects with caries experience but not statistically significant $\left(\chi^{2}=1.95\right.$, $\mathrm{p}=0.09)$ (Table 7).

No statistically significant relation between caries and food habits was found. In particular, no correlation between carbohydrates consumption and caries $\left(\chi^{2}=1.89, \mathrm{p}=0.1\right)$ (Table 8$)$, nor daily diary consumption and caries prevention $\left(\chi^{2}=2.1, \mathrm{p}=0.08\right)$ (Table 9). Positive association was found between the scholarly level of mothers $\left(\chi^{2}=\right.$ 7.74, $\mathrm{p}<0.01)$ and fathers $\left(\chi^{2}=6.35, \mathrm{P}=0.01\right)$, and the presence of caries (Table 10).

No association was found in group of adolescents brushing their teeth more time a day than who did not brush them assiduously $\left(\chi^{2}=5.15 ; \mathrm{p}=0.27\right)$ (Table 11).

\section{Discussion}

This study was designed and carried out in the schools of Naples, one of the most populous cities in Italy and one with the highest birth 
rates. The OMS goal for the year 2000 , i.e. a DMFT value $\leq 3$, was reached and in agreement with the results of other surveys [10,20,21].

$\mathrm{D}$ value in the DMFT score was always the highest; the variations observed among the different districts for mean values of DMFT may

\begin{tabular}{|c|c|c|c|c|}
\hline \multirow{2}{*}{ Dental elements } & \multicolumn{2}{|c|}{ Maxillary } & \multicolumn{2}{c|}{ Mandibular } \\
\cline { 2 - 5 } & Right\% & Left\% & Right\% & Left\% \\
\hline Permanent central incisor & 1.06 & - & - & - \\
\hline Permanent lateral incisor & - & 0.34 & 0.34 & - \\
\hline Deciduous canine & - & - & - & - \\
\hline Permanent canine & - & - & 0.70 & - \\
\hline First deciduous molar & 0.34 & - & - & - \\
\hline Second deciduous molar & 2.82 & 1.75 & 2.11 & 2.82 \\
\hline Permanent first premolar & 2.45 & 2.11 & 0.70 & 1.06 \\
\hline Permanent second premolar & 1.06 & 1.06 & 1.41 & 0.70 \\
\hline First permanent molar & 46.83 & 36.27 & 40.84 & 25.00 \\
\hline Second permanent molar & 9.86 & 7.38 & 10.55 & 11.62 \\
\hline
\end{tabular}

Table 3: Caries prevalence.

\begin{tabular}{|c|c|}
\hline Occlusal Variables & Number of Subjects (\%) \\
\hline Molar class I & $307(57.37)$ \\
\hline Canine class II & $11(2.04)$ \\
\hline Canine class III & - \\
\hline Molar class II & $184(34.33)$ \\
\hline Class II, II division & $7(1.33)$ \\
\hline Molar class III & $26(4.94)$ \\
\hline Overjet $>4 \mathrm{~mm}$ & $3(0.56)$ \\
\hline Overjet $0-4 \mathrm{~mm}$ & $446(83.21)$ \\
\hline Overjet $<0 \mathrm{~mm}$ & $87(16.22)$ \\
\hline Overbite $>4 \mathrm{~mm}$ & $3(0.56)$ \\
\hline Overbite $0-4 \mathrm{~mm}$ & $427(79.65)$ \\
\hline Overbite $<0 \mathrm{~mm}$ & $106(19.76)$ \\
\hline Median line & $172(32.09)$ \\
\hline Crossbite & $63(11.75)$ \\
\hline Monolateral crossbite & $51(9.51)$ \\
\hline Bilateral crossbite & $12(2.24)$ \\
\hline Crowding & $253(47.20)$ \\
\hline Diastema & $123(22.95)$ \\
\hline Table $4:$ Frequey & \\
\hline
\end{tabular}

Table 4: Frequency of occlusal variables in the sample.

\begin{tabular}{|c|c|c|c|}
\hline Category & $\begin{array}{c}\text { DMFT>0 } \\
\mathrm{n}(\%)\end{array}$ & $\begin{array}{c}\text { DMFT=0 } \\
\mathrm{n}(\%)\end{array}$ & OR (95\% CI) \\
\hline Class I & $176(54.83)$ & $131(60.92)$ & $1.34(1.07 / 1.68)$ \\
\hline Class I with>OVJ & $7(2.18)$ & $4(1.86)$ & $1.75(0.51 / 5.98)$ \\
\hline Class II, division I & $113(35 \%)$ & $71(33 \%)$ & $1.6(1.04 / 1.91)$ \\
\hline Class II, division II & $4(1.25)$ & $3(1.40)$ & $1.33(0.30 / 5.96)$ \\
\hline Class III & $14(4.36)$ & $3(1.40)$ & $4.67(1.34 / 16.24)$ \\
\hline Class III, subdivision & $7(2.18)$ & $3(1.40)$ & $2.33(0.60 / 9.02)$ \\
\hline
\end{tabular}

$X^{2}$ for trend $=3.55 ; p=0.04$

Table 5: Caries prevalence (DMFT $>0)$ across malocclusion.

\begin{tabular}{|c|c|c|c|}
\hline & $\begin{array}{c}\text { DMFT=0 } \\
\mathrm{n}(\%)\end{array}$ & $\begin{array}{c}\text { DMFT>0 } \\
\mathrm{n}(\%)\end{array}$ & $\begin{array}{c}\mathbf{X}^{\mathbf{2}} \text { for trend; } \\
\text { p-value }\end{array}$ \\
\hline Crossbite & $39(61.90)$ & $24(38.09)$ & $3.96 ; 0.04^{*}$ \\
\hline
\end{tabular}

Table 6: Caries prevalence (DMFT $>0)$ and crossbite.

\begin{tabular}{|c|c|c|c|}
\hline & $\begin{array}{c}\text { DMFT=0 } \\
\mathrm{n}(\%)\end{array}$ & $\begin{array}{c}\text { DMFT>0 } \\
\mathrm{n}(\%)\end{array}$ & $\begin{array}{c}\mathbf{X}^{\mathbf{2}} \text { for trend; } \\
\mathbf{p} \text {-value }\end{array}$ \\
\hline Dental crowding & $130(51.37)$ & $123(48.62)$ & $1.95 ; 0.09$ \\
\hline
\end{tabular}

Table 7: Caries prevalence (DMFT $>0)$ and crowding.

\begin{tabular}{|c|c|c|c|}
\hline Carbohydrate & $\begin{array}{c}\text { DMFT }>0 \\
\mathrm{n}(\%)\end{array}$ & $\begin{array}{c}\text { DMFT=0 } \\
\mathrm{n}(\%)\end{array}$ & $\begin{array}{c}\mathrm{X}^{2} \text { for trend } \\
\text { p-value }\end{array}$ \\
\hline $\begin{array}{c}\text { Sweets* } \\
\text { None }\end{array}$ & $24(8.45)$ & $26(10.31)$ & \\
Low & $114(40.14)$ & $97(38.49)$ & \\
\hline Normal & $70(24.64)$ & $73(28.96)$ & \\
High & $76(26.76)$ & $56(22.22)$ & \multirow{2}{*}{1.89} \\
\hline Cake** & $24(8.4)$ & $22(8.73)$ & 0.1 \\
None & $104(36.61)$ & $101(40.07)$ & \\
\hline Low & $87(29.57)$ & $74(29.36)$ & \\
\hline Normal & $69(24.29)$ & $55(21.82)$ & \\
\hline High & $122(42.95)$ & $108(42.85)$ & \\
\hline Sweet Snacks & & \\
\hline
\end{tabular}

*Sweets: None (no sweets), low (seldom), normal (1-2 times per day), high (>twice a day)

${ }^{* *}$ Cake: None (no cake), low (seldom), normal (once a day), high (>once a day)

Table 8: Correlation between prevalence of caries and carbohydrate.

\begin{tabular}{|c|c|c|c|}
\hline & $\begin{array}{c}\text { DMFT>0 } \\
(\mathrm{n} \%)\end{array}$ & $\begin{array}{c}\text { DMFT=0 } \\
(\mathrm{n} \%)\end{array}$ & $\begin{array}{c}\mathrm{x}^{2} \text { for trend } \\
\text { p-value }\end{array}$ \\
\hline $\begin{array}{c}\text { Dairy* } \\
\text { None }\end{array}$ & $37(58.72)$ & $26(41.27)$ & \\
Low & $57(54.81)$ & $47(45.18)$ & 2.1 \\
Normal & $150(50.00)$ & $150(50.00)$ & 0.08 \\
High & $40(57.96)$ & $29(42.03)$ & \\
\hline
\end{tabular}

*None (no dairy), low (<twice a week), normal (2-4 times per week), high ( $>4$ times per week)

Table 9: Correlation between prevalence of caries and dairy products.

\begin{tabular}{|c|c|c|c|c|}
\hline Education & $\begin{array}{c}\text { DMFT>0 } \\
n(\%)\end{array}$ & $\begin{array}{c}\text { DMFT }=0 \\
n(\%)\end{array}$ & OR $(95 \% \mathrm{Cl})$ & $\begin{array}{l}\mathrm{X}^{2} \text { for } \\
\text { trend } \\
\text { p-value }\end{array}$ \\
\hline \multicolumn{5}{|c|}{ Mother } \\
\hline Low grade & $72(27.91)$ & $38(21.60)$ & $1.90(1.28 / 2.80)$ & \multirow{4}{*}{$\begin{array}{c}7.74 \\
<0.01^{*}\end{array}$} \\
\hline Medium grade & $80(31.00)$ & $45(25.57)$ & $1.78(1.23 / 2.56)$ & \\
\hline College & $79(30.62)$ & $58(32.95)$ & $1.36(0.97 / 1.91)$ & \\
\hline Degree & $27(10.47)$ & $35(19.88)$ & $0.77(0.47 / 1.27)$ & \\
\hline \multicolumn{5}{|c|}{ Father } \\
\hline Low grade & $51(20.00)$ & $22(12.72)$ & $2.31(1.40 / 14.86)$ & \multirow{4}{*}{$\begin{array}{l}6.35 \\
0.01^{*}\end{array}$} \\
\hline Medium grade & $88(34.51)$ & $56(32.37)$ & $1.57(1.12 / 2.20)$ & \\
\hline College & $76(29.80)$ & $55(31.79)$ & $1.38(0.98 / 1.95)$ & \\
\hline Degree & $40(15.69)$ & $40(23.12)$ & $1.00(0.64 / 1.55)$ & \\
\hline
\end{tabular}

Table 10: Caries prevalence (DMFT>0) across parents scholarly level.

\begin{tabular}{|c|c|c|c|}
\hline Frequency & $\begin{array}{c}\text { DMFT>0 } \\
\mathrm{n}(\%)\end{array}$ & $\begin{array}{c}\text { DMFT=0 } \\
\mathrm{n}(\%)\end{array}$ & p-value \\
\hline Never & $11(7.74)$ & $7(2.77)$ & - \\
\hline Once a day & $24(8.45)$ & $21(30.55)$ & - \\
\hline 2 times a day & $99(34.85)$ & $77(30.55)$ & 5.15 \\
\hline 3 times a day & $107(37.67)$ & $117(46.43)$ & 0.27 \\
\hline 4 times a day & $42(14.78)$ & $30(11.90)$ & - \\
\hline
\end{tabular}

Table 11: Prevalence of caries and brushing teeth.

be due to social and/or cultural differences $[7,22,23]$. Higher values of DMFT were found in students who had no intake of milk or dairy products. This finding may be in line with earlier studies showing that milk and dairy products consumption was associated with a less frequency of caries even if in this report the correlation was present but not statistically significant unlike other studies [22,24-26], this discrepancy is probably due to the multifaceted etiology of caries.

In the last few years, a distinct association between oral hygiene and prevention of dental caries has been demonstrated [27-29]. Studies found out that the prevalence of caries was not related to correct oral hygiene practices, as also reported in other surveys, strengthening the 
hypothesis of a multifactorial origin of caries [9,14,23,25,27-34]. Several studies evaluating the relationship between crowding and dental caries have shown contradictory results, probably due to small sample size included in the studies $[33,35,36]$.

The hypothesis that occlusal disorders may increase the risk of caries was also tested. The need of any orthodontic treatment should not be linked to a decreased risk of future caries, although the higher prevalence of caries was associated with the crossbite [30,32,37]. Today, the malocclusions and space anomalies are mainly not considered as predictors of caries [31]. However, further studies are needed to monitor whether South Italy students will achieve the ambitious DMFT goal of $<1.5$ for the year 2020 [17,18,38-41].

\section{Conclusion}

Positive relationship was found between dental caries, parents' educational status and crossbite, whereas carious lesions, food intake, oral hygiene and the other type of occlusal disorder did not reveal any significant association in 12-year-old school children of Naples in the Southern Italy.

\section{References}

1. Addy M, Griffiths GS, Dummer PM, Kingdon A, Hicks R (1988) The association between tooth irregularity and plaque accumulation, gingivitis, and caries in 11-12-year-old children. Eur J Orthod 10: 76-83.

2. Auad SM, Waterhouse PJ, Nunn JH, Moynihan PJ (2009) Dental caries and its association with sociodemographic, erosion, and diet in schoolchildren from southest Brazil. Pediatr Dent 31: 229-235.

3. Campus G, Cagetti MG, Senna A, Sacco G, Strohmenger L, et al. (2008) Caries prevalence and need for dental care in 13-18-year-olds in the Municipality of Milan, Italy. Community Dent Health 25: 237-242.

4. Campus G, Solinas G, Cagetti MG, Senna A, Minelli L, et al. (2007) National Pathfinder survey of 12-year-old Children's Oral Health in Italy. Caries Res 41: 512-517.

5. Llena C, Leyda A, Forner L, Garcet S (2015) Association between the number of early carious lesions and diet in children with a high prevalence of caries. Eur J Paediatr Dent 16: 7-12.

6. Hafez HS, Shaarawy SM, Al-Sakiti AA, Mostafa YA (2012) Dental crowding as a caries risk factor: a systematic review. Am J Orthod Dentofacial Orthop 142: 443-450.

7. Angelillo IF, Anfosso R, Nobile CG, Pavia M (1998) Prevalence of dental caries in schoolchildren in Italy. Eur J Epidemiol 14: 351-357.

8. Angelillo IF, Romano F, Fortunato L, Montanaro D (1990) Prevalence of dental caries and enamel defects in children living in areas with different water fluoride concentrations. Community Dent Health 7: 229-236.

9. Petti S, Cairella G, Tarsitani G (2000) Rampant early childhood dental decay: an example from Italy. J Public Health Dent 60: 159-166.

10. Perinetti G, Varvara G, Esposito P (2006) Prevalence of dental caries in schoolchildren living in rural and urban areas: results from the first region-wide Italian survey. Oral Health Prev Dent 4: 199-207.

11. Cordasco G, Crupi P, Lo Giudice G, Matarese G, Romeo U (1989) Epidemiological study of the frequency of caries and malocclusion in schoolage children. Stomatol Mediterr 9: 179-184.

12. Feldens CA, Dos Santos Dullius Al, Kramer PF, Scapini A, Busato AL, et al (2015) Impact of malocclusion and dentofacial anomalies on the prevalence and severity of dental caries among adolescents. Angle Orthod 85: 1027-1034.

13. Gaikwad SS, Gheware A, Kamatagi L, Pasumarthy S, Pawar V, et al. (2015) Dental caries and its relationship to malocclusion in permanent dentition among 12-15 year old school going children. J Int Oral Health 6: 27-30.

14. Pappalardo G, Caltabiano M, Cicciù D (1979) Relationship between dental caries and malocclusion in a random sample of 378 pupils of the elementary schools in Catania. Riv Ital Stomatol 48: 41-49.

15. Perillo L, Masucci C, Ferro F, Apicella D, Baccetti T (2010) Prevalence of orthodontic treatment need in southern Italian schoolchildren. Eur J Orthod 32: 49-53.

16. World Health Organization (1997) Oral Health Surveys: Basic Methods. (4 $4^{\text {th }}$ edn), World Health Organization, Geneva.

17. Cvikl B, Haubenberger-Praml G, Drabo P, Hagmann M, Moritz A, et al. (2014) Migration background is associated with caries in Viennese school children, even if parents have received a higher education. BMC Oral Health 14: 51.

18. Hobdell M, Petersen PE, Clarkson J, Johnson N (2003) Global goals for oral health 2020. Int Dent J 53: 285-288.

19. Guido AJ, Martinez Mier EA, Soto A, Eggertsson H, Sanders BJ, et al. (2011) Caries prevalence and its association with brushing habits, water availability and the intake of sugared beverages. Int J Paediatr Dent 21: 432-440.

20. Mazza C, Strohmenger L, Campus G, Cagetti MG, Caruso F, et al. (2010) Ora Health status of children living in Gorom-Gorom, Oudalan District, BurkinaFaso. Int J Dent 2010: 597251

21. Szoke J, Petersen PE (2000) Evidence for dental caries decline among children in an East European country (Hungary). Community Dent Oral Epidemiol 28: $155-160$.

22. da Silveira Moreira R (2012) In: Oral Health Care - Pediatric, Research, Epidemiology and Clinical Practices. InTech, Rijeka, Croatia.

23. Majorana A, Cagetti MG, Bardellini E, Amadori F, Conti G, et al. (2014) Feeding and smoking habits as cumulative risk factors for early childhood caries in toddlers, after adjustment for several behavioral determinants: a retrospective study. BMC Pediatr 14: 45

24. Källestål C, Wall S (2002) Socio-economic effect on caries. Incidence data among Swedish 12-14-year-olds. Community Dent Oral Epidemiol 30: 108-114.

25. Moynihan P, Petersen PE (2004) Diet, nutrition and the prevention of dental diseases. Public Health Nut 7: 201-226.

26. Uceda PR, Sanzone LA, Phillips CL, Roberts MW (2013) Fluoride Exposure Caregiver Education, and Decayed, Missing, Filled Teeth (DMFT) in 2-5 yearold English or Spanish Speaking Children. Open Dent J 13: 175-180.

27. Lopes RM, Domingues GG, Junqueira SR, Araujo ME, Frias AC (2013) Conditional factors for untreated caries in 12-year-old children in the city of São Paulo. Braz Oral Res 27: 376-381.

28. Maltz M, Jardim JJ, Alves LS (2010) Health promotion and dental caries. Braz Oral Res 24: 18-25.

29. Musaiger AO, Al-Mannai M, Abduljawad E (2014) Association of oral hygiene habits and food intake with the risk of dental caries among undergraduate university women in Saudi Arabia. Int J Adolesc Med Health 26: 585-589.

30. Migale D, Barbato E, Bossù M, Ferro R, Ottolenghi L (2009) Oral health and malocclusion in 10-to-11 years-old children in southern Italy. Eur $\mathrm{J}$ Paediatr Dent 10: 13-18.

31. Mtaya M, Brudvik $P$, Astrøm AN (2009) Prevalence of malocclusion and its relationship with socio-demographic factors, dental caries, and oral hygiene in 12 to 14-year-old Tanzanian schoolchildren. Eur J Orthod 31: 467-476.

32. Nieto García VM, Nieto García MA, Lacalle Remigio JR, Abdel-Kader Martín $L$ (2001) Oral health of school children in Ceuta. Influences of age, sex, ethnic background and socioeconomic level. Rev Esp Salud Publica 75: 541-549.

33. Perillo L, Castaldo MI, Cannavale R, Longobardi A, Grassia V, et al. (2011) Evaluation of long-term effects in patients treated with Fränkel-2 appliance. Eur J Paediatr Dent 12: 261-266.

34. Quashie-Williams R, daCosta OO, Isiekwe MC (2010) Oral habits, prevalence and effects on occlusion of 4-15 year old school children in Lagos, Nigeria. Niger Postgrad Med J 17: 113-117.

35. Giugliano D, d'Apuzzo F, Jamilian A, Perillo L (2015) Relationship between malocclusion and oral habits. Current Res Dent 5: 17-21.

36. Laganà G, Masucci C, Fabi F, Bollero P, Cozza P (2013) Prevalence of malocclusions, oral habits and orthodontic treatment need in a 7- to 15-yearold schoolchildren population in Tirana. Prog Orthod 14: 12.

37. Perillo L, Padricelli G, Isola G, Femiano F, Chiodini P, et al. (2012 ) Class I malocclusion division 1: a new classification method by cephalometric analysis. Eur J Paediatr Dent.13: 192-196. 
Citation: Perillo L, Cocco F, Cagetti MG, Giugliano D, Bardellini E, et al. (2016) Influence of Occlusal Disorders, Food Intake and Oral Hygiene Habits on Dental Caries in Adolescents: A Cross-Sectional Study. Dentistry 6: 358. doi:10.4172/2161-1122.1000358

38. World Health Organization Regional Office for Europe (1999) Health21: the health for all policy framework for the WHO European Region. World Health Organization, Geneva.

39. Fleming P (2015) Timetable for oral prevention in childhood - a current opinion. Prog Orthod 16: 27.
40. Angelillo IF, Torre I, Nobile CG, Villari P (1999) Caries and fluorosis prevalence in communities with different concentrations of fluoride in the water. Caries Res 33: 114-122.

41. Rajab LD, Petersen PE, Baqain Z, Bakaeen G (2014) Oral health status among 6- and 12-year-old Jordanian Schoolchildren. Oral Health Prev Dent 12: 99-107. 